\title{
Características geoquímicas da Suíte G1, arco magmático do Orógeno Araçuaí, entre Governador Valadares e Ipanema, MG
}

\author{
Geochemical characteristics of the G1 Suite, magmatic arc of the Araçuaí \\ Orogen, between Governador Valadares and Ipanema, MG
}

Leonardo E. da Silva Gonçalves

DEGEO-EM-UFOP

E-mail: leonardo@degeo.ufop.br

\section{Fernando Flecha de Alkmim \\ DEGEO-EM-UFOP \\ E-mail:alkmim@degeo.ufop.br}

\section{Antônio Carlos Pedrosa-}

Soares

CPMTC-ICG-UFMG

E-mail: pedrosa@pq.cnpq.br

\section{Resumo}

Apresenta-se, nesse trabalho, o resultado de uma investigação petrológicogeoquímica realizada em granitóides da Suíte G1 do Orógeno Araçuaí, localizados entre as cidades de Governador Valadares e Ipanema (MG). Nessa região, a Suíte G1 é constituída pelas litofácies enderbito-tonalítica, granodiorítica-tonalítica e granítica, as quais possuem características químicas semelhantes às de uma série cálcio-alcalina expandida, metaluminosa a levemente peraluminosa do tipo I. Os dados obtidos revelaram, também, que as litofácies individualizadas correspondem a distintos estágios evolutivos do magmatismo granítico, com as fácies enderbitotonalítica e granítica, representando os extremos menos e mais diferenciados, respectivamente. Em conjunto com as rochas vulcânicas do Grupo Rio Doce, os componentes da Suíte G1 estudados materializam o edifício plutônico-vulcânico do arco magmático do Orógeno Araçuaí, formado em uma margem continental entre 630 e 585 Ma.

Palavras-chave: Suíte G1, Orógeno Araçuaí, Grupo Rio Doce, arco magmático, Neoproterozóico.

\begin{abstract}
This article presents the results of a petrogenetic and geochemical study carried out for granitoid plutons of the G1 Suite of the Araçuaí orogen, exposed in the region between Governador Valadares and Ipanema (MG). The G1 Suite comprises three distinct lithofacies, namely enderbitic-tonalitic, granodioritictonalitic and granitic, which show chemical characteristics similar to an expanded calc-alkaline, metaluminous to slightly peraluminous I-type assemblage. Investigation results indicate that each individual G1 lithofacies represents an evolutionary stage of granitic magmatism, the enderbitic-tonalitic and granitic corresponding to the least and most differentiated components, respectively. Together with the volcanic rocks of the Rio Doce Group, the studied G1 rocks made up the magmatic arc of the Araçuaí orogen, developed on a continental margin between 630 and 585 Ma.
\end{abstract}

Keywords: G1 Suite, Araçuaí orogen, Rio Doce Group, magmatic arc, Neoproterozoic. 


\section{Introdução}

O Orógeno Araçuaí-Congo Ocidental é um dos vários orógenos brasiliano-panafricanos gerados na aglutinação de massas continentais, aglutinação esta que culminou na formação do Gondwana Ocidental (Pedrosa-Soares et al., 2001, Alkmim et al., 2006). Possui a particularidade de ter se desenvolvido em um ambiente parcialmente confinado, circundado a norte, oeste e leste pelos crátons do São Francisco e Congo. A abertura do Oceano Atlântico, iniciada no Cretáceo, o dividiu em dois segmentos: o Orógeno Araçuaí, situado entre o Cráton do São Francisco e a margem continental brasileira (Pedrosa-Soares et al., 2001, 2008, Alkmim et al., 2006) e sua contraparte no sudoeste africano, a Faixa Congo Ocidental (Tack et al., 2001).

A evolução tectônica do Orógeno Araçuaí é caracterizada por diferentes episódios de magmatismo granítico, discriminados em função de seus atributos estruturais, petrológicos, geoquímicos e geocronológicos nas suítes G1 (pré-colisional), G2 (sin-colisional), G3 (tardi- a pós-colisional), G4 e G5 (pós-colisionais) (Pedrosa-Soares \& Wiedemann-Leonardos, 2000; recentemente atualizado em Pedrosa-Soares et al., 2008).

A Suíte G1 tem recebido especial atenção, uma vez que materializa o arco magmático cálcio-alcalino, formado no estágio pré-colisional do Orógeno Araçuaí (Pedrosa-Soares et al., 2001, 2008; Alkmim et al., 2006). O intervalo de tempo no qual se formou a Suíte G1 está bem estabelecido por datações U-Pb entre 630-585 Ma (e.g., Nalini Jr., 1997, Pedrosa-Soares et al., 2001, 2008). No entanto, a distribuição espacial e muitas das características dos corpos que compõem esta suíte ainda não são de todo conhecidas.

Com o objetivo de melhor delimitar corpos pertencentes e candidatos a pertencerem à Suíte G1, investigar a sua gênese e, em última análise, contribuir para a reconstrução da paleogeografia pré-colisional do Orógeno Araçuaí-
Congo Ocidental, a região entre os meridianos $42^{\circ} 10^{\prime}-41^{\circ} 20^{\prime} \mathrm{W}$ e paralelos $18^{\circ} 50^{\prime}$ - $19^{\circ} 50^{\prime} \mathrm{S}$, limitada a norte por Governador Valadares e a sul por Ipanema, foi estudada do ponto de vista geoquímico e petrogenético (Gonçalves, 2009, Figura 1). Nessa região, plútons, localmente conhecidos como Derribadinha, São Vítor, Galiléia, Cuieté Velho e Alto Capim, acham-se expostos em uma área de 113 x $57 \mathrm{~km}$ e se alojam nas rochas do Complexo Pocrane (de idade incerta) e do Grupo Rio Doce (de idade Neoproterozóica; Vieira, 2007, Figura 1). Além disso, fazem contatos marcados por zonas de cisalhamento com as rochas dos complexos Mantiqueira e Juiz de Fora, os quais representam o embasamento regional, e são cortados por rochas intrusivas graníticas das Suítes G2 e G5, sin e pós-colisionais, respectivamente (Pedrosa-Soares \& Wiedemann-Leonardos, 2000).

\section{Materiais e métodos}

Para a caracterização geoquímica e petrogenética, foram selecionadas 26 amostras de rochas plutônicas e uma amostra de rocha vulcânica pertencente à Formação Palmital do Sul do Grupo Rio Doce (Gonçalves, 2009). Para fins comparativos, foram utilizados os dados obtidos por Vieira (2007) em quatro amostras de rochas vulcânicas do Grupo Rio Doce. As amostras selecionadas foram analisadas pelo Laboratório ACME (GO), após as rotinas convencionais de britagem e moagem realizadas no Laboratório de Preparação de Amostras para Geoquímica e Geocronologia (LOPAG) do Departamento de Geologia da UFOP. Por meio de Espectrômetro de Emissão em Plasma Indutivamente Acoplado (ICP-ES), foram analisados os elementos maiores. Essa análise foi seguida por fusão em metaborato/tetraborato de lítio e digestão em ácido nítrico diluído, sendo a perda ao fogo (LOI) determinada pela diferença de peso da amostra antes e depois do aquecimento a $1000^{\circ} \mathrm{C}$. Os elementos-traços foram analisados no Espectrômetro de Massa em Plasma Indutivamente Acoplado (ICP-MS), sendo que os elementos terras-raras (ETR) e os elementos refratários passaram por fusão em metaborato/tetraborato de lítio, sendo que tal processo foi seguido de digestão em ácido nítrico e os metais preciosos e base (Au, Ag, As, Bi, Cd, Cu, $\mathrm{Hg}, \mathrm{Mo}, \mathrm{Ni}, \mathrm{Pb}, \mathrm{Sb}, \mathrm{Se}, \mathrm{Tl}, \mathrm{Zn}$ ) passaram, ainda, por diluição em água régia.

\section{A suíte G1 entre Governador Valadares e Ipanema (MG) Litofácies da Suíte G1}

Na área investigada, as rochas granitóides da Suíte G1 ocorrem na forma de três litofácies distintas, quais sejam: enderbito-tonalítica, granodiorítica-tonalítica e granítica. A fácies enderbito-tonalítica é caracterizada por rochas de composição tonalítica, com ou sem ortopiroxênio, de tonalidade cinza a levemente esverdeada. A fácies granodiorítica-tonalítica envolve rochas de tonalidade cinza, com freqüentes enclaves melanocráticos. A fácies granítica é composta por rochas leucocráticas, com raros enclaves. A sua distribuição na área de estudo é mostrada na Figura 1.

\section{Elementos maiores, traços e terras raras.}

Amostras das três litofácies discriminadas foram analisadas e apresentaram teores de $\mathrm{SiO}_{2}$ entre 56,03\% e 75,75\%, tratando-se, portanto, de rochas intermediárias a ácidas. Os teores de $\mathrm{Al}_{2} \mathrm{O}_{3}$ variam entre 12,51\% e $18,63 \%$ e os teores de $\mathrm{K}_{2} \mathrm{O}$ estão entre $0,85 \%$ e $6,22 \%$. Nos diagramas binários Harker (sílica versus outros óxidos), observam-se, para as amostras da Suíte G1 (Figura 2-I), uma correlação positiva, com dispersão para $\mathrm{K}_{2} \mathrm{O}$, uma correlação negativa, para $\mathrm{TiO}_{2}, \mathrm{Al}_{2} \mathrm{O}_{3}$, $\mathrm{MgO}, \mathrm{CaO}, \mathrm{FeO}_{\text {total }}$ e $\mathrm{MnO}$, e grande dispersão, para $\mathrm{Na}_{2} \mathrm{O}$. As amostras das rochas vulcânicas do Grupo Rio Doce apresentam relações similares às das rochas plutônicas, quando se comparam os mesmos diagramas, e uma correlação positiva também é observada para $\mathrm{Na}_{2} \mathrm{O}$ 
Leonardo E. da Silva Gonçalves et al.

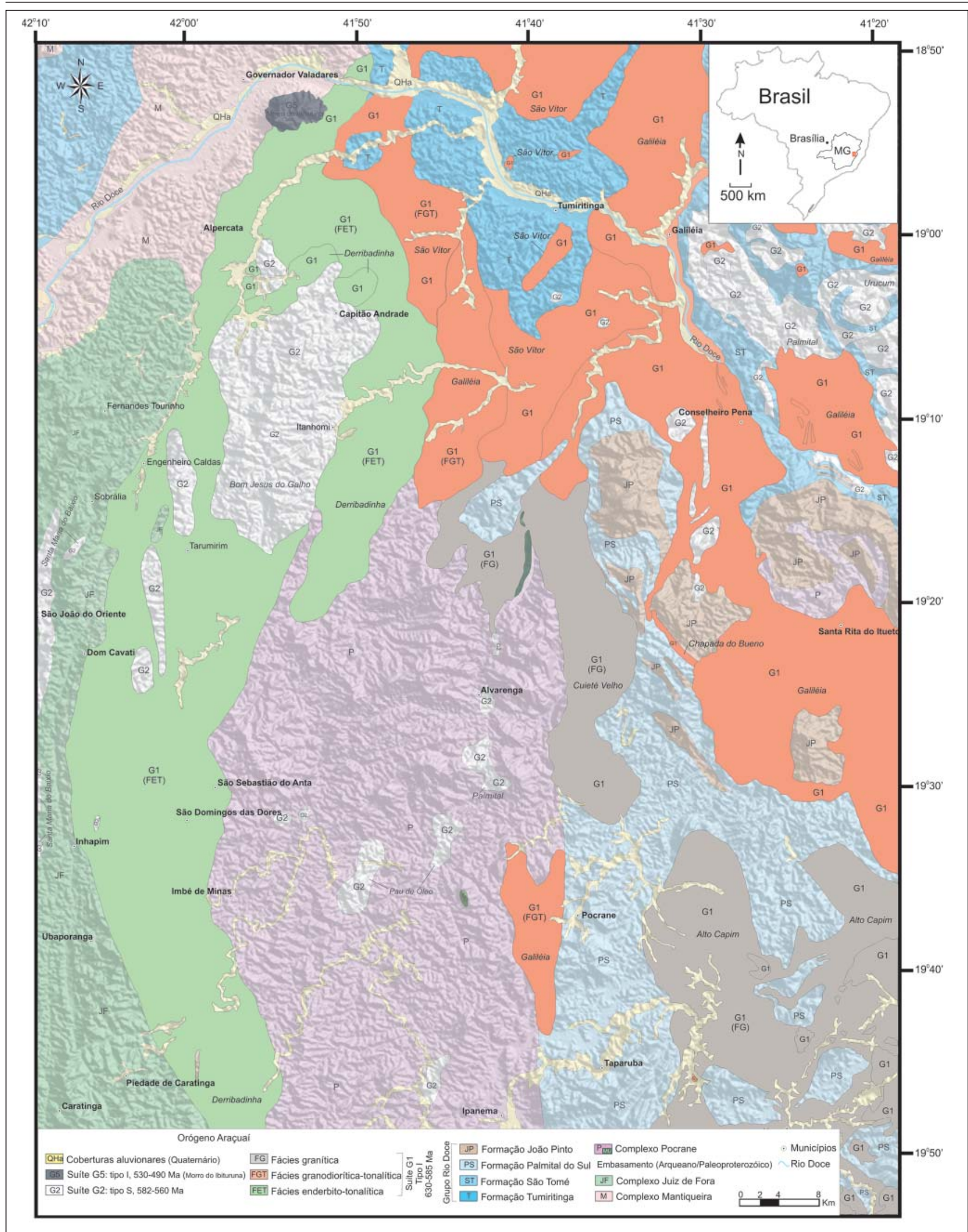

Figura 1 - Mapa geológico da região compreendida entre Governador Valadares e Ipanema, MG, enfatizando a distribuição das litofácies discriminadas para a Suíte G1 (modificado de Gonçalves, 2009). 


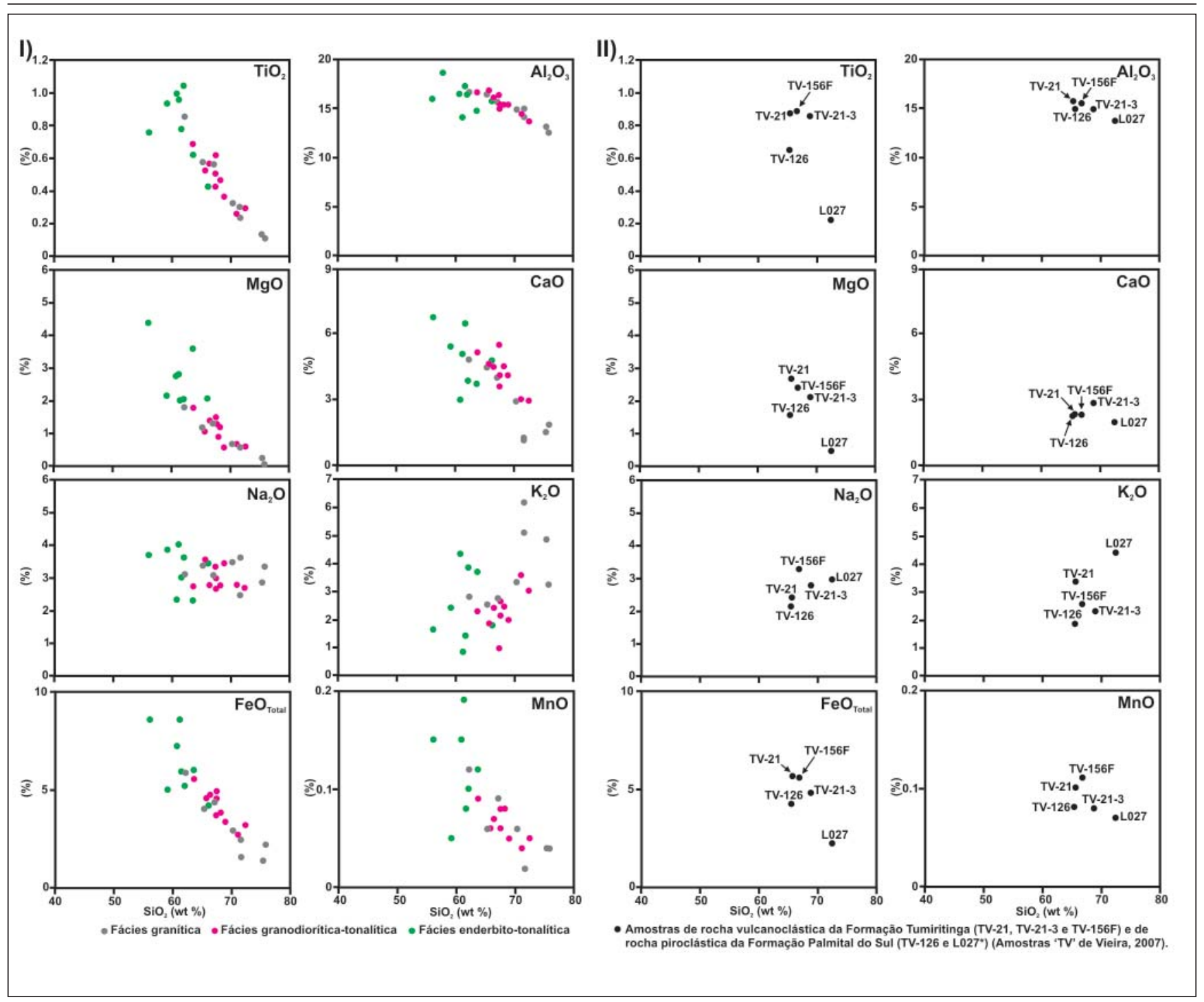

Figura 2 - Diagrama binários de variação Harker, sílica versus outros óxidos (modificado de Bhatia, 1983). I) amostras da Suíte G1 e II) amostras do Grupo Rio Doce.

(Figura 2-II). Essas correlações são compatíveis com a cristalização de minerais ferromagnesianos (biotita \pm anfibólio \pm piroxênio), feldspatos (plagioclásio \pm microclina \pm ortoclásio) e quartzo, como minerais essenciais, e minerais acessórios, como zircão, granada, titanita, apatita e rutilo, todos eles presentes nas rochas estudadas.

No diagrama de classificação R1 x R2, as rochas são classificadas como tonalito e granodiorito, com diorito e granito subordinados (Figura 3-I). As rochas vulcânicas do Grupo Rio Doce são classificadas no diagrama TAS como dacito (amostras de Vieira, 2007) e como riolito (Figura 3-II).
A relação $\mathrm{SiO}_{2} \times(\mathrm{A} / \mathrm{CNK})$ bem como os diagramas AFM e $\mathrm{SiO}_{2}$ x $\mathrm{K}_{2} \mathrm{O}$ mostram características químicas de uma série cálcio-alcalina expandida, metaluminosa a levemente peraluminosa, do tipo I, com índice de saturação em alumina entre 0,50 e 1,11 (Figuras 3-III, IV e V). Os teores de $\mathrm{K}_{2} \mathrm{O}$, entre 1,89 e 4,43 , caracterizam uma série de médio a alto potássio para as rochas vulcânicas (Figura 3-VI).

Com base na relação $(\mathrm{Y}+\mathrm{Nb})$ x Rb, que descrimina diferentes ambientes tectônicos (Pearce et al., 1984), as rochas analisadas se dispõem, principalmente, no campo de arco vulcânico, com duas amostras no limite com o campo intraplaca (Figura 4-I). Os atributos geoquímicos, segundo o diagrama R1 x R2 (Batchelor \& Bowden, 1985), evidenciam marcante assinatura de arco vulcânico pré-colisional com fracionados de manto, corroborando, entre outros, os trabalhos de Nalini Jr. (1997), Pedrosa-Soares et al. (2001) e Nalini Jr. et al. (2005) (Figura 4-II).

Quando normalizados para meteoritos condríticos, que representam amostras de material pouco fracionado (Rollinson, 1993), os padrões de terras-raras apresentados pelas rochas estudadas são muito semelhante aos apresentados para a Suíte Galiléia (Nalini Jr., 1997, Nalini Jr. et al., 1998). 
Leonardo E. da Silva Gonçalves et al.

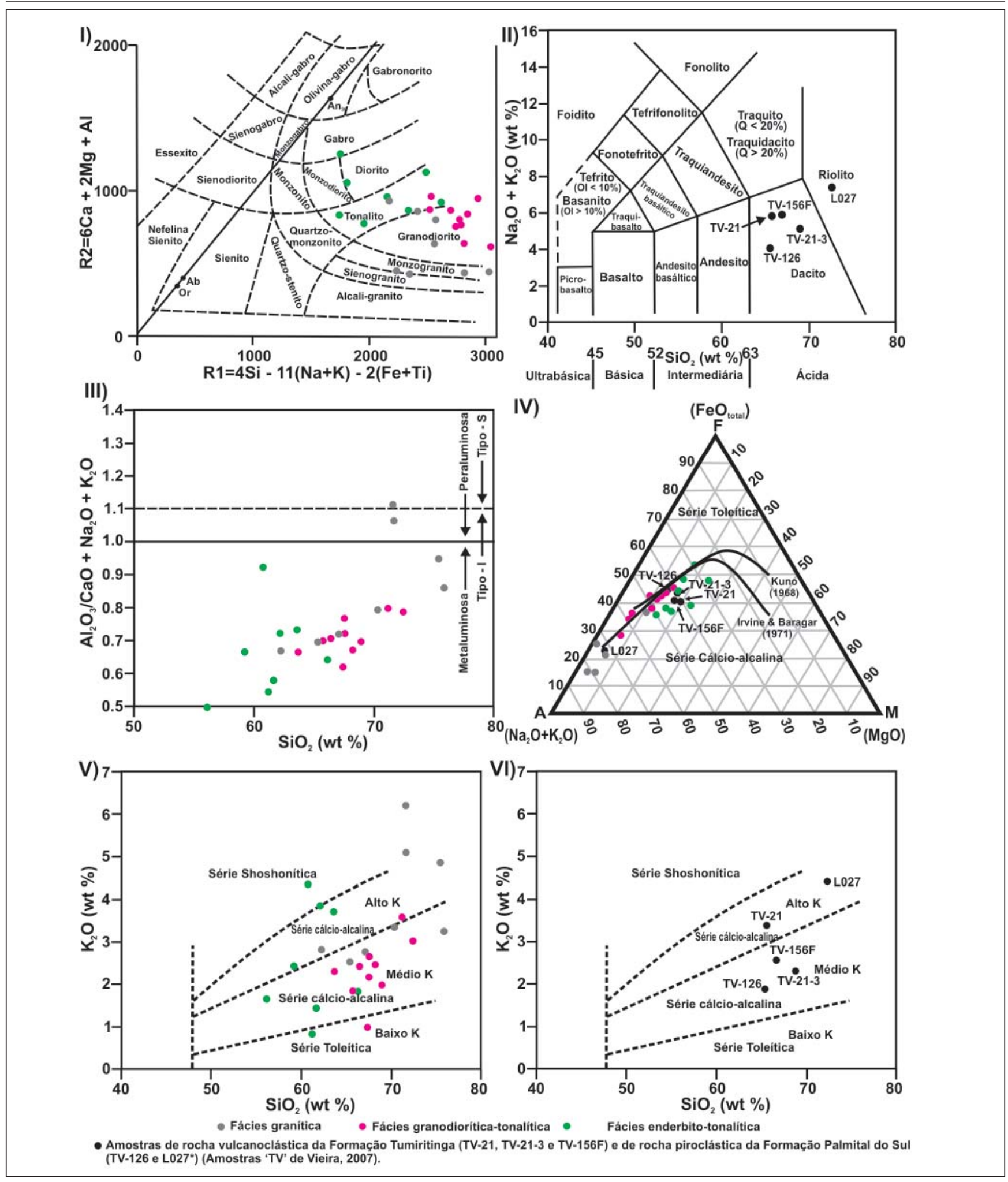

Figura 3 - I) Diagrama de classificação para rochas plutônicas da Suíte G1 usando os parâmetros R1 e R2 (modificado de De la Roche et al., 1980), proporções calculadas em milications. II) Diagrama de classificação para rochas vulcânicas do Grupo Rio Doce, usando o conteúdo de álcalis total x sílica (TAS), modificado de Le Maitre et al. (1989). Q=quartzo normativo, Ol=olivina normativa. III) Posição das amostras da Suíte G1 no diagrama $\mathrm{SiO}_{2}$ x A/CNK, modificado de Chapell e White (1974). IV) Diagrama mostrando o limite entre o campo cálcio-alcalino e o campo tholeiítico, modificado de Rickwood (1989). V e VI) Diagramas de rochas subalcalinas usando $\mathrm{K}_{2} \mathrm{O}$ versus sílica. A nomenclatura baixo, médio e alto potássio é a adotada por Le Maitre et al. (1989) e as séries tholeiítica, cálcio-alcalina, cálcio-alcalina de alto K e shoshonítica é a nomenclatura usada por Rickwood (1989). 
Características geoquímicas da Suíte G1, arco magmático do Orógeno Araçuaí...

Tanto as rochas plutônicas da Suíte G1, quanto as rochas vulcânicas associadas, mostram um ligeiro fracionamento dos elementos terras-raras leves em relação aos elementos terras-raras pesados, o que é bem representado pela razão (La/ Lu)N com máximo igual a 46,84. Todas as amostras exibem uma anomalia negativa de $\mathrm{Eu}(\mathrm{Eu} / \mathrm{Eu} *)$, com valores entre 0,08 (amostra L197) e 0,62 (amostra L246), para as rochas plutônicas da Suíte G1, e valores iguais a 0,13 (L027), 0,16 (TV-21) e 0,18 (TV-156F), para as rochas vulcânicas do Grupo Rio Doce (Figuras 4-III e 4-IV).

Embora haja certa homogeneidade química entre os granitóides Derribadi- nha (fácies enderbito-tonalítica), Galiléia - São Vítor (fácies granodioríticatonalítica), Cuieté Velho e Alto Capim (fácies granítica) e similaridade geral com a Suíte Galiléia em sua área-tipo (tal como caracterizada por Nalini Jr., 1997), certas particularidades das três litofácies são evidenciadas. Os corpos da porção oeste (Figura 1), que compõem a litofácies enderbito-tonalítica, representam, na área de estudo, o grupo de rochas menos evoluídas.

$\mathrm{O}$ teor médio de $\mathrm{SiO}_{2}$ para as rochas da litofácies enderbito-tonalítica é de 61,29\%, tratando-se, portanto, de rochas intermediárias. Já o teor médio das demais litofácies é de 68,74\%, o que as caracteriza como rochas ácidas. Para a litofácies enderbito-tonalítica, a anomalia de Eu é, em média, de 0,230; para as demais fácies é de 0,223.

Anomalias negativas de Eu decorrem da cristalização de minerais que, no início do processo de cristalização magmática, incorporam Eu em sua estrutura cristalina. Como o Eu tem grande afinidade química com o cálcio, a cristalização de plagioclásio tem um importante papel neste processo. Se a litofácies enderbito-tonalítica (Tonalito Derribadinha) representa a fase menos evoluída, precoce, do arco magmático do Orógeno Araçuaí, os valores normalizados de Eu deveriam registrar esse

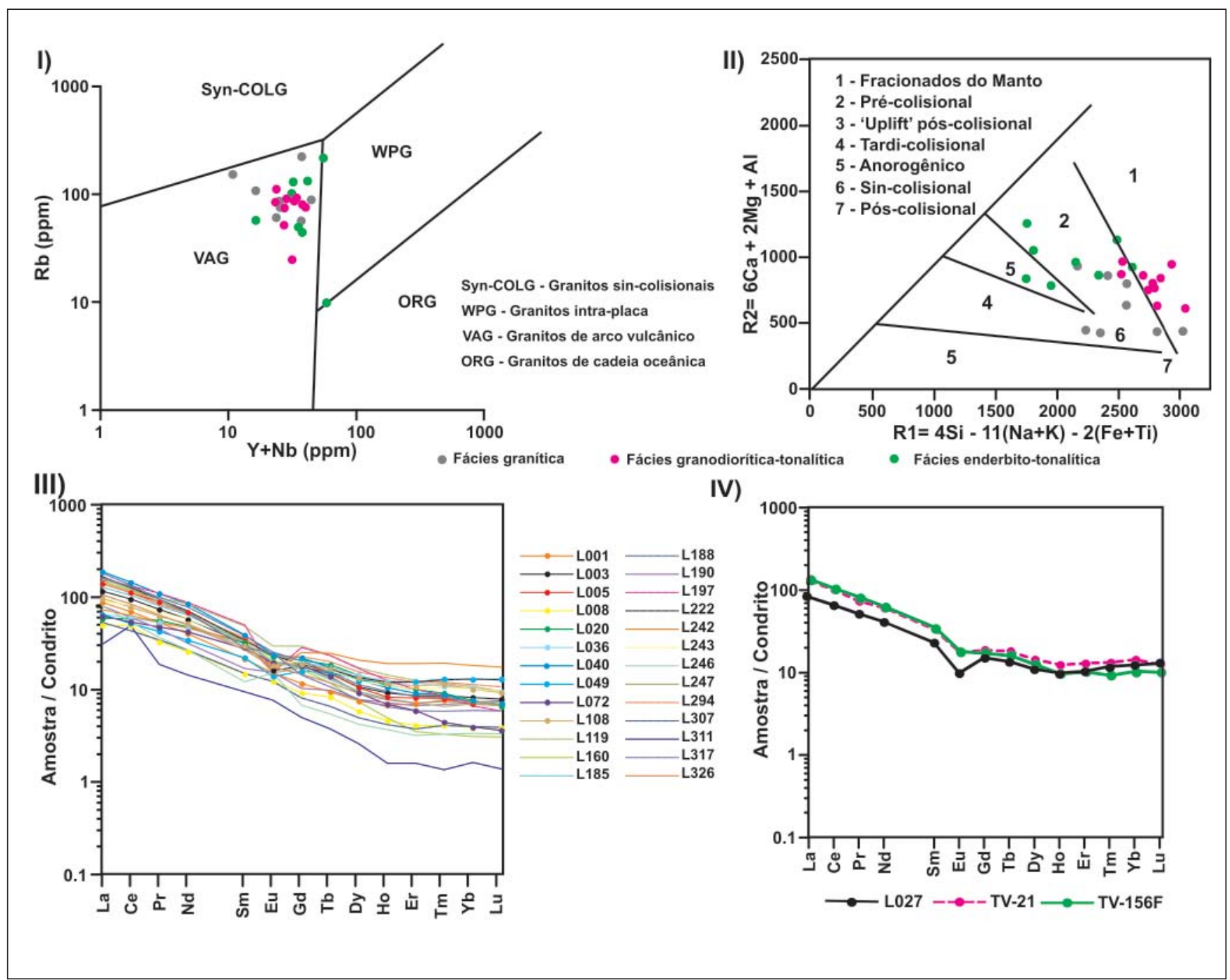

Figura 4 - Diagramas de discriminação de ambientes tectônicos para rochas graníticas: I) modificado de Pearce et al. (1984) e II) modificado de Batchelor e Bowden (1985). Diagramas de ETR, com normalização por condrito segundo valores de Nakamura (1974), III) amostras da Suíte G1 e IV) amostras do Grupo Rio Doce (Amostras "TV" de Vieira, 2007). 
fato. Tal não é o caso. Entretanto o valor mais alto de 0,62, ou seja, a anomalia menos pronunciada, foi encontrado para a amostra L246, que pertence à fácies enderbito-tonalítica. Em contraste, o valor mais baixo, de 0,08 , anomalia mais acentuada, foi encontrado na amostra L197, que pertence ao plúton Alto Capim da fácies granítica.

O diagrama da Figura 5 mostra a relação existente entre $\mathrm{Ba} / \mathrm{Sr}$, $\mathrm{Fe}_{2} \mathrm{O}_{3}+\mathrm{MgO}+\mathrm{MnO}+\mathrm{TiO}_{2}$ e $\mathrm{Rb}$ e sugere, novamente, a interpretação de menos evoluída para a fácies enderbito-tonalítica. Deve-se ter em mente que o plagioclásio rico em Ca é formado no início do processo de cristalização magmática e a razão $\mathrm{Ba} / \mathrm{Sr}$ tem a finalidade de mostrar a incorporação de plagioclásio durante esse processo. Caso houvesse um decréscimo dessa razão, o resultado poderia ser devido à incorporação de Rb no feldspato potássico (Nalini et al., 2005). O aumento de Rb poderia, concomitantemente, implicar um aumento de Ba, ou seja, o aumento de Rb é, grosseiramente, proporcional ao aumento de $\mathrm{Ba}$ e inversamente proporcional ao aumento de Sr. Como a cristalização de plagioclásio implica consumo de $\mathrm{Sr}$, que possui afinidade química com $\mathrm{Ca}$, o trend observado, para as amostras da fácies enderbito-tonalítica, com razões $\mathrm{Ba} / \mathrm{Sr}$ inferior a 20, implica, em primeira linha, a cristalização de plagioclásio em detrimento ao feldspato potássico (Figura 5). Portanto os valores mais baixos da razão $\mathrm{Ba} / \mathrm{Sr}$ (valores mais altos de $\mathrm{Sr}$ ) associados às relações de anomalias de Eu indicam a cristalização precoce das rochas da fácies enderbito-tonalítica, em relação às demais fácies estudadas.

Os elementos terras-raras leves (La-Nd) são mais incompatíveis se comparados aos pesados (Er-Lu). Desse modo, o conteúdo dos mesmos deve nos dizer sobre a evolução das etapas de cristalização. Em valores médios, os corpos da fácies enderbito-tonalítica apresentam $\Sigma$ ETR_leves=143,06 ppm, menor que o valor apresentado pelas demais, que é de $\Sigma$ ETR_leves=168,86 ppm. O conteúdo médio do somatório dos elementos terras-raras pesados, por sua vez, é de 5,125 (ppm), para a fácies enderbito-tonalítica, e de 4,009 (ppm), para as demais fácies. Portanto, novamente, se comprova a diferenciação existente entre os corpos da fácies enderbito-tonalítica e os plútons Galiléia, São Vítor, Cuieté Velho e Alto Capim, que compõem as demais fácies discriminadas na área de estudo. As demais tendências observadas sugerem a fácies granítica como mais evoluída ainda que a fácies granodiorítica-tonalítica.

\section{Conclusões}

As características geoquímicas e petrogenéticas apresentadas pelas rochas da Suíte G1 entre Governador Valadares e Ipanema (MG) permitem interpretá-las como resultantes de magmatismo de natureza cálcio-alcalina, metaluminosa a levemente peraluminosa, do tipo I. São, no seu conjunto, muito semelhantes às características da Suíte Galiléia, já caracterizada como representante típica de arco magmático (Nalini Jr., 1997, Pedrosa-Soares \& WiedemannLeonardos, 2000). As diferentes litofá- cies discriminadas representam, por seu turno, diferentes estágios da evolução da parte plutônica do arco magmático. O componente mais primitivo e profundo do arco corresponde à fácies enderbitotonalítica e as demais, aos membros mais evoluídos e rasos. Em conjunto com dacitos e riolitos do Grupo Rio Doce, as rochas da Suíte G1 caracterizam o edifício plutônico-vulcânico do arco magmático do Orógeno Araçuaí.

\section{Agradecimentos}

Os autores manifestam seus agradecimentos ao Conselho Nacional de Desenvolvimento Científico e Tecnológico (CNPq), o qual concedeu bolsa de mestrado ao primeiro autor e bolsas de produtividade em pesquisa aos demais autores. Ao Departamento de Geologia da Universidade Federal de Ouro Preto, pelo apoio logístico e infra-estrutura oferecidos, em particular ao LOPAG, pela preparação das amostras para análise geoquímica. Revisores anônimos, com críticas e sugestões, contribuíram para o aprimoramento do manuscrito.

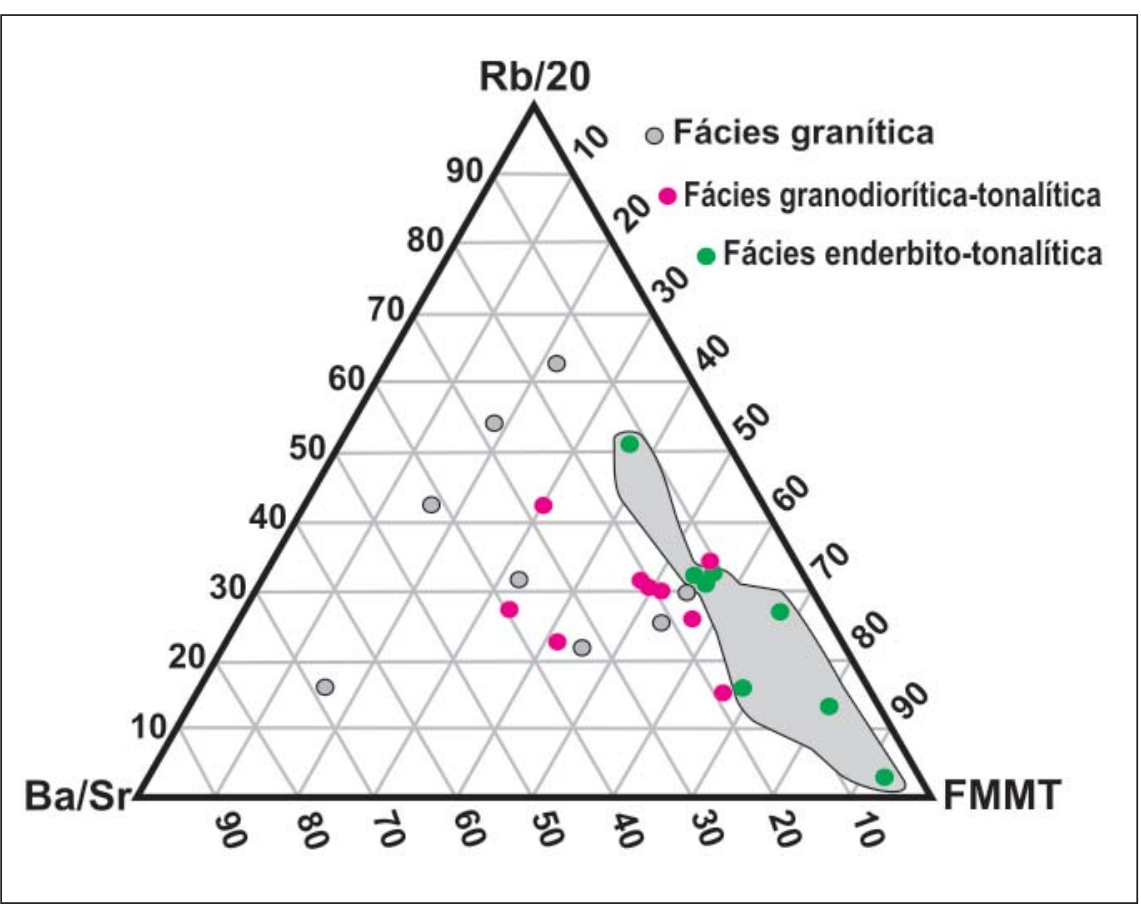

Figura 5 - Disposição das amostras da Suíte G1 no diagrama ternário (Ba/Sr x Br/20 x FMMT); em destaque as amostras da fácies enderbito-tonalítica. 
Características geoquímicas da Suíte G1, arco magmático do Orógeno Araçuaí...

\section{Referências bibliográficas}

ALKMIM, F. F., MARSHAK, S., PEDROSA-SOARES, A. C., PERES, G.G., CRUZ, S. C. P., WHITTINGTON, A. Kinematic evolution of the Araçuaí-West Congo orogen in Brazil and Africa: Nutcracker tectonics during the Neoproterozoic assembly of Gondwana. Precambrian Research, n. 149, p. 43-64, 2006.

BATCHELOR, R. A., BOWDEN, P. Petrogenetic interpretation of granitoids series using multicationic parameters. Chemical Geology, n. 48, p. 43-55, 1985.

BHATIA, M. R. Plate tectonics and geochemical composition of sandstones. Journal of Geology, n. 91, p. 611-627, 1983.

CHAPELL, B. W., WHITE, A. J. R. Two contrasting granite types. Pacific. Geol., n. 8, p. 173-174, 1974.

DE LA ROCHE, H., LETERRIER, J., GRANDE CLAUDE, P., MARCHAL, M. A classification of volcanic and plutonics rocks using R1-R2 diagrams and major element analyses - its relationships and current nomenclature. Chemical Geology, n. 29, p. 183-21, 1980.

GONCALVES, L. E. da S. Características gerais e história deformacional da Suíte Granítica G1, entre Governador Valadares e Ipanema, MG. Ouro Preto: Universidade Federal de Ouro Preto - DEGEO-UFOP, 2009. 112p. (Dissertação de Mestrado).

LE MAITRE, R. W., BATEMAN, P., DUDEK, A., KELLER, J., LAMEYERE, LE BAS M. J., SABINE, P. A., SCHMID, R., SORENSEN, H., STRECKEISEN, A., WOOLLEY, A. R., ZANETTIN, B. A classification of igneous rocks and glossary of terms. Blackwell, Oxford, 1989.
NAKAMURA, N. Determination of REE, Ba, Fe, Mg, Na and K in carbonaceous and ordinary chondrites. Geochim. Cosmochim. Acta, n. 38, p. 757-775, 1974.

NALINI Jr., H. A. Caractérisation des suites magmatiques néoprotérozoiques de la region de Conselheiro Pena et Galiléia (Minas Gerais, Brésil). Etude géochimique et structurale des suites Galiléia et Urucum et relations avec les pegmatites à éléments rares associées. Paris: Ecole des Mines de Saint Etienne et Ecole des Mines de Paris, 1997. 237p. (Tese de Doutorado).

NALINI Jr., H. A, BILAL, E., CORREIA NEVES, J. M. Mineralogical, Geochemical and Isotopic Constraints of Neoproterozoic Granitois (Urucum and Galileia Suites) Eastern Minas Gerais State, Brazil. In: INTERNATIONAL CONFERENCE OM PRECAMBRIAN AND CRATONIC TECTONICS. Ouro Preto, Brazil: Universidade Federal de Ouro Preto, Abstracts, p. 44-46, 1998.

NALINI Jr., H. A., MACHADO, R., BILAL, E. Geoquímica e Petrogênese da Suíte Galiléia: Exemplo de Magmatismo Tipo-I Metaluminoso Pré-Colisional Neoproterozóico da Região do Médio Vale do Rio Doce (MG). Revista Brasileira de Geociências, n. 35, v.4, p. 23-34, 2005.

PEARCE, J. A., HARRIS, N. B. W., TINDLE, A. G. Trace element discrimination diagrams for the tectonic interpretation of granitic rocks. Journal of Petrolology, n. 25, p. 956-983, 1984.

PEDROSA-SOARES, A. C., WIEDEMANN-LEONARDOS, C. M. Evolution of the Araçuaí belt and its connection to the Ribeira Belt, Eastern Brazil. In: CORDANI U. G., MILANI E. J., THOMAZ FILHO A., CAMPOS D. A. (eds.) Tectonic Evolution of South America. International Geological Congress, Rio de Janeiro, p. 265-285, 2000.

PEDROSA-SOARES, A. C., NOCE, C. M., WIEDEMANN, C. M., PINTO, C. P. The Araçuaí-West Congo orogen in Brazil: An overview of a confined orogen formed during Gondwanland assembly. Precambrian Research, n. 110, p. 307-323, 2001.

PEDROSA-SOARES, A. C., ALKMIM, F. F., TACK, L., NOCE, C. M., BABINSKI, M., SILVA, L. C., MARTINS-NETO, M. A. Similarities and differences between the Brazilian and African counterparts of the Neoproterozoic Araçuaí-WestCongo orogen. In: PANKHURST, J.R., TROUW, R.A.J., BRITO NEVES, B.B., DE WIT, M.J. (eds.) West Gondwana: Pre-Cenozoic Correlations across the South Atlantic Region. Geological Society, London, v. 294, p. 153-172, 2008. (Special Publications).

RICKWOOD, P. C. Boundary lines within petrologic diagrams which use oxides of major and minor elements. Lithos, n. 22, p. 247-263, 1989.

ROLLINSON, H. R. Using geochemical data: evaluation, presentation, interpretation. New York: John Wiley \& Sons, Inc., 1993. 352p.

TACK, L., WINGATE, M. T. D., LIÉGEOIS, J. P., FERNANDEZ-ALONSO, M., DEBLOND, A. Early Neoproterozoic magmatism (1000-900 Ma) of the Zadinian and Mayumbian Groups (Bas-Congo): onset of Rodinian rifting at the western edge of the Congo Craton. Precambrian Research, n. 110, p. 277-306, 2001.

VIEIRA, V. S. Significado do Grupo Rio Doce no Contexto do Orógeno Araçuaí. Belo Horizonte: IGC-UFMG, 2007. 117p. (Tese de Doutorado).

Artigo recebido em 13/10/2009 e aprovado em 23/04/2010.

\section{www.rem.com.br}

